\title{
MOS Capacitor Characteristics of 3C-SiC Films Deposited on Si Substrates at $1270^{\circ} \mathrm{C}$
}

Li Wang ${ }^{1}$, Sima Dimitrijev ${ }^{1}$, Leonie Hold ${ }^{1}$, Frederick Kong ${ }^{1}$, Philip Tanner ${ }^{1}$, Jisheng Han ${ }^{1}$, and Gunter Wagner $^{2}$

${ }^{1}$ Queensland Microtechnology Facility and Griffith School of Engineering, Griffith University, 170 Kessels Road, Brisbane, 4111, Australia

${ }^{2}$ Institute of Crystal Growth, Max-Born-Str. 2, Berlin, 12489, Germany

\begin{abstract}
$\mathrm{SiC}$ films were deposited on $\mathrm{Si}$ substrate by low pressure hot-wall CVD using $\mathrm{C}_{3} \mathrm{H}_{8}(5 \%$ in $\left.\mathrm{H}_{2}\right)-\mathrm{SiH}_{4}\left(2.5 \%\right.$ in $\left.\mathrm{H}_{2}\right)-\mathrm{H}_{2}$ gas system at $1270^{\circ} \mathrm{C}$ and $1370^{\circ} \mathrm{C}$. MOS capacitors were fabricated on the grown $3 \mathrm{C}-\mathrm{SiC}$ films. In this paper, we compare the electrical characteristics of MOS capacitors fabricated on $3 \mathrm{C}-\mathrm{SiC}$ films deposited at high and low temperatures, $1370^{\circ} \mathrm{C}$ and $1270^{\circ} \mathrm{C}$, respectively. The cross-sectional TEM images indicate similar $\mathrm{SiC} / \mathrm{Si}$ interface microstructural quality for $3 \mathrm{C}-\mathrm{SiC}$ films deposited at different temperatures, though a quicker elimination rate of stacking fault with increasing thickness at $1370^{\circ} \mathrm{C}$, and rocking curves from XRD measurements indicate better crystalline perfection at $1370^{\circ} \mathrm{C}$. The average surface roughness measurements performed by an atomic force microscope show that the surface roughness increases with elevated deposition temperature. The MOS capacitors were characterized by high-frequency capacitance-voltage (HFCV), conductance-voltage $(G-V)$, and current-voltage $(I-V)$ measurements at room temperature. The MOS capacitors fabricated on both films exhibit good and almost identical $C$ - $V$ characteristics. Measurements of current-voltage characteristics in accumulation region showed smaller leakage for the film deposited at $1270^{\circ} \mathrm{C}$. It is concluded that the decrease of the deposition temperature from $1370^{\circ} \mathrm{C}$ to $1270^{\circ} \mathrm{C}$ does not bring any remarkable negative impact on the interface properties of fabricated MOS capacitors.
\end{abstract}

\section{INTRODUCTION}

The limitation imposed by $\mathrm{Si}$ and GaAs devices able to operate under extreme conditions has encouraged some research groups to investigate other semiconductors with wider energy gap. Hetero-epitaxial growth of $3 \mathrm{C} \mathrm{SiC}$ films on silicon substrate has been attracting increasing attention [1,2] because SiC-based devices can be integrated with the mainstream Si devices showing great potential in both electronic and micro/nano-mechanical applications. The conventional technique of deposition of $3 \mathrm{C} \mathrm{SiC}$ films on silicon substrate is chemical vapour deposition (CVD) using separate precursors such as $\mathrm{SiH}_{4}$ as $\mathrm{Si}$ source and $\mathrm{C}_{3} \mathrm{H}_{8}$ as carbon source [3]. There is a report showing that the best crystal quality and purity is usually obtained at relatively high temperature around $1350^{\circ} \mathrm{C}$ to $1400{ }^{\circ} \mathrm{C}$ for the deposition on $\mathrm{Si}$ substrate [4]. Ciobanu et al published a paper about the traps at the interface of $3 \mathrm{C}-\mathrm{SiC} / \mathrm{SiO}_{2} \mathrm{MOS}$ capacitor, in which the $3 \mathrm{C}-\mathrm{SiC}$ film was deposited homoepitaxially by CVD at $1600{ }^{\circ} \mathrm{C}$ [5].

Heteroepitaxially grown $3 \mathrm{C}-\mathrm{SiC}$ films on $\mathrm{Si}$ substrates by hot-wall $\mathrm{CVD}$ at $1370^{\circ} \mathrm{C}$ and $1270^{\circ} \mathrm{C}$ were used for the analysis presented in this paper. The electrical characteristics of metaloxide-semiconductor (MOS) capacitors fabricated on these films were analyzed to investigate the influence of deposition temperature. 


\section{EXPERIMENT}

SiC films were deposited on $\mathrm{Si}$ substrates using $\mathrm{C}_{3} \mathrm{H}_{8}\left(5 \%\right.$ in $\left.\mathrm{H}_{2}\right)-\mathrm{SiH}_{4}\left(2.5 \%\right.$ in $\left.\mathrm{H}_{2}\right)-\mathrm{H}_{2}$ gas system at $1270^{\circ} \mathrm{C}$ and $1370^{\circ} \mathrm{C}$ in a low pressure hot-wall CVD reactor. A detailed description of the CVD-system was already published elsewhere [6]. Ultra pure $\mathrm{H}_{2}$ was used as the carrier gas, and the deposition of $3 \mathrm{C}-\mathrm{SiC}$ films took place with the total pressure in the reactor of 150 mbar. MOS capacitors were fabricated on grown 3C-SiC films using the following process. The bare $3 \mathrm{C}-\mathrm{SiC} / \mathrm{Si}$ wafers were first cleaned in a mixture of $\mathrm{H}_{2} \mathrm{SO}_{4}$ and $\mathrm{H}_{2} \mathrm{O}_{2}$, followed by an RCA clean. This was then followed by $1 \% \mathrm{HF}$ dip for $1 \mathrm{~min}$. For better $\mathrm{SiC} / \mathrm{SiO}_{2}$ interface quality, the gate oxide layers were grown in $100 \% \mathrm{NO}$ at $1160^{\circ} \mathrm{C}$ [5]. After that aluminum was thermally evaporated to form the gate electrodes and square capacitors with area of $0.0025 \mathrm{~cm}^{2}$ were then defined by photolithography. The MOS capacitors were characterized by highfrequency capacitance-voltage (HFCV), conductance-voltage $(G-V)$ and current-voltage $(I-V)$ measurements at room temperature. The HFCV measurements were performed at the sweep rate of $0.1 \mathrm{~V} / \mathrm{s}$ and the sweep range from $2 \mathrm{~V}$ to $-14 \mathrm{~V}$, using a computer-controlled HP4284A LCR meter. The $I-V$ measurements were performed at the sweep rate of $0.1 \mathrm{~V} / \mathrm{s}$ and the sweep range from $0 \mathrm{~V}$ to $15 \mathrm{~V}$, using a computer-controlled HP4145 meter. All the measurements were performed under light-tight and electrically-shielded conditions. The electrical analysis was complemented by transmission electron microscopy, high resolution X-ray diffraction (HRXRD) rocking curve and atomic-force microscopy to obtain information on structural characteristics and average surface roughness of the deposited $3 \mathrm{C}-\mathrm{SiC}$ films.

\section{RESULTS AND DISCUSSION}

It is usually believed that higher temperature helps to improve the film quality. The fullwidth at half-maximum (FWHM) of 3C-SiC (002) HRXRD rocking curve decreases from 670 arcsec for sample A (deposited at $1270^{\circ} \mathrm{C}, 4.6 \mu \mathrm{m}$ ) to $380 \operatorname{arcsec}$ for sample B (deposited at $1370^{\circ} \mathrm{C}, 4.9 \mu \mathrm{m}$ ), as shown in figure 1 . The cross-sectional TEM images indicate similar SiC/Si interface micro-structural quality for both samples (shown in figure 2), while sample B shows a quicker elimination rate of stacking fault with increasing thickness than sample A. No etch pits are observed in either sample. All these results indicate a better crystalline quality at higher deposition temperature.
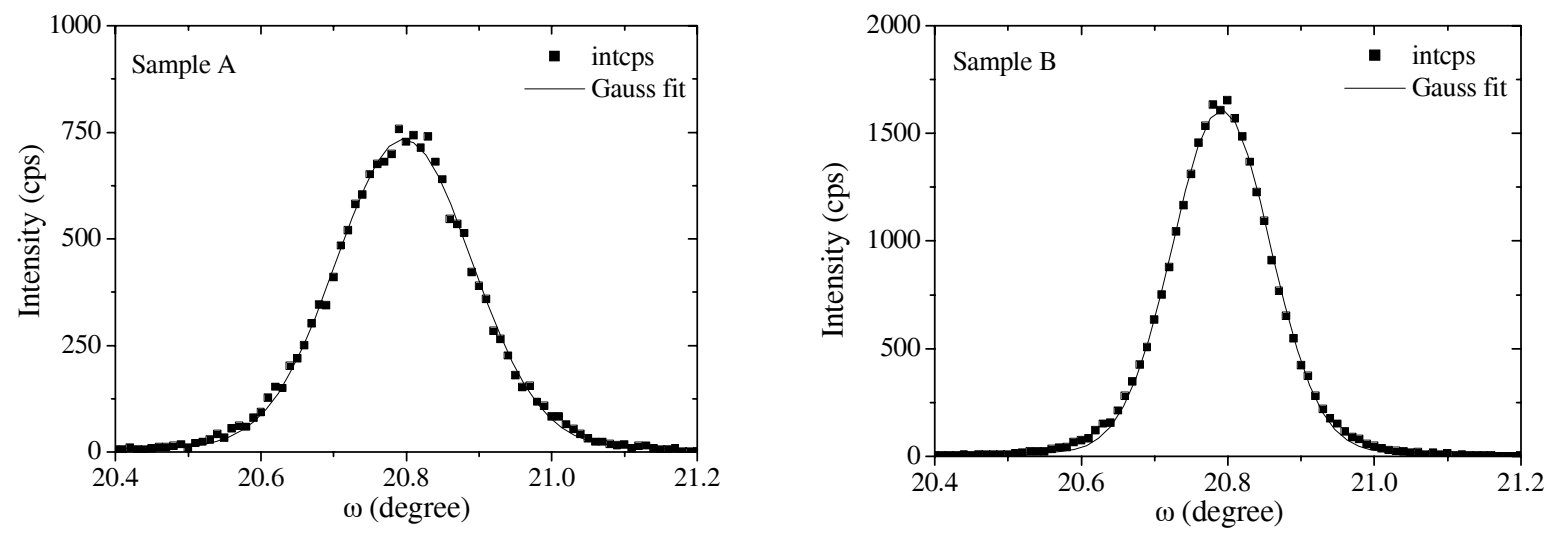

Figure $13 \mathrm{C}-\mathrm{SiC}(002) \mathrm{HRXRD}$ rocking curves of sample A (deposited at $1270^{\circ} \mathrm{C}$ ) and sample $\mathrm{B}\left(\right.$ deposited at $\left.1370^{\circ} \mathrm{C}\right)$ 

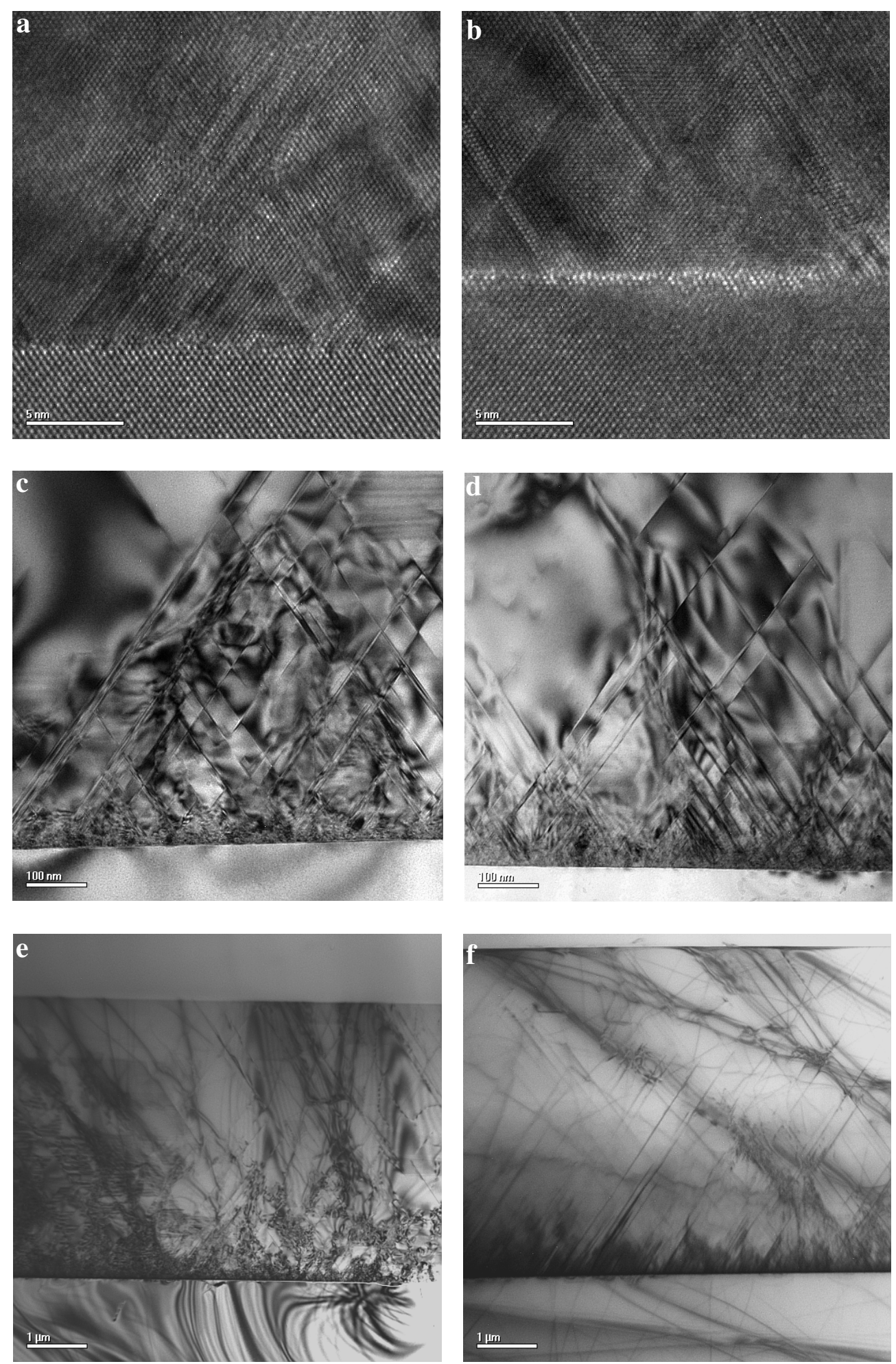

Figure 2 TEM micrographs of $\mathrm{SiC}$ films deposited at $1270{ }^{\circ} \mathrm{C}(\mathrm{a}, \mathrm{c}$, e, for sample $\mathrm{A})$ and $1370{ }^{\circ} \mathrm{C}$ (b, d, f, for sample B). 
The average surface roughness ( $\mathrm{Ra}$ ) measurements performed by an atomic force microscope show that the Ra increases with elevated deposition temperature, from $10.8 \mathrm{~nm}$ for sample A to $34 \mathrm{~nm}$ for sample B. A smoother surface is preferred for improving device performance.

The MOS capacitors fabricated on both samples exhibit good and almost identical C-V characteristics (shown in Figures 3 and 4). The gate-oxide thickness, determined from the accumulation capacitance, is $28.3 \mathrm{~nm}$. According to the measured $C$ - $V$ curves, both samples are confirmed to be $n$-type conduction and when fitted to theoretical curves, electron concentrations of $7 \times 10^{15} \mathrm{~cm}^{-3}$ (sample A) and $5 \times 10^{15} \mathrm{~cm}^{-3}$ (sample B) were determined. Minimum distortion

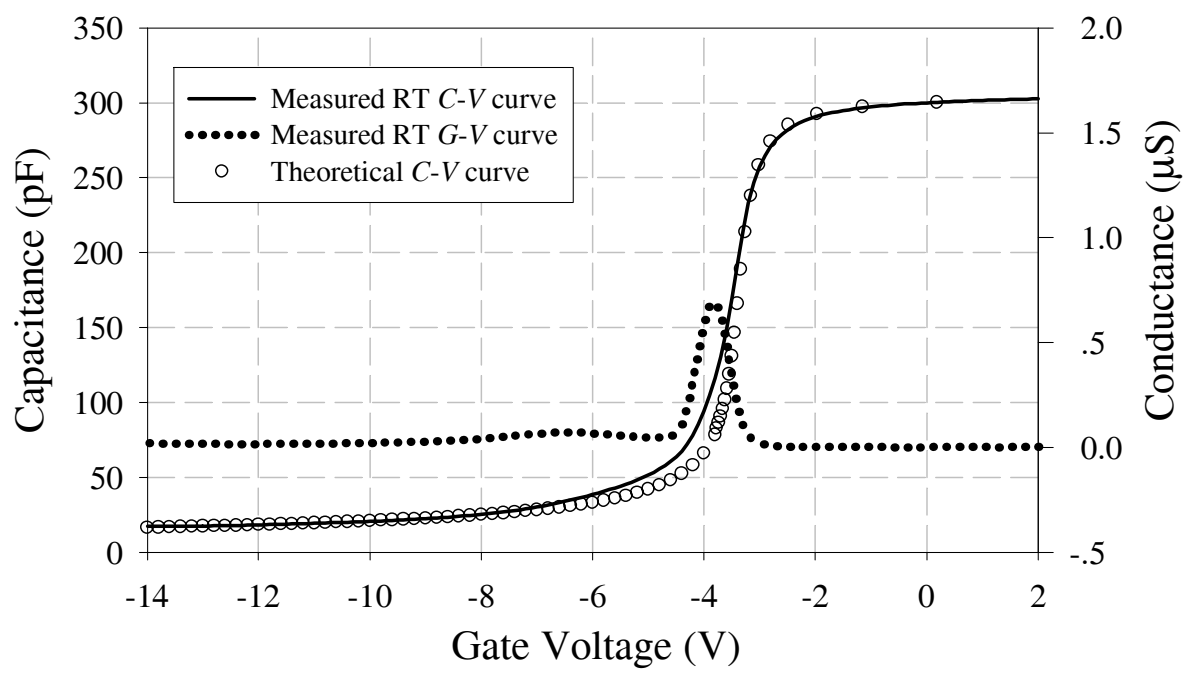

Figure 3 High frequency $C$ - $V$ and $G$ - $V$ curves for the $3 \mathrm{C}$-SiC film deposited at $1270^{\circ} \mathrm{C}$ (sample A).

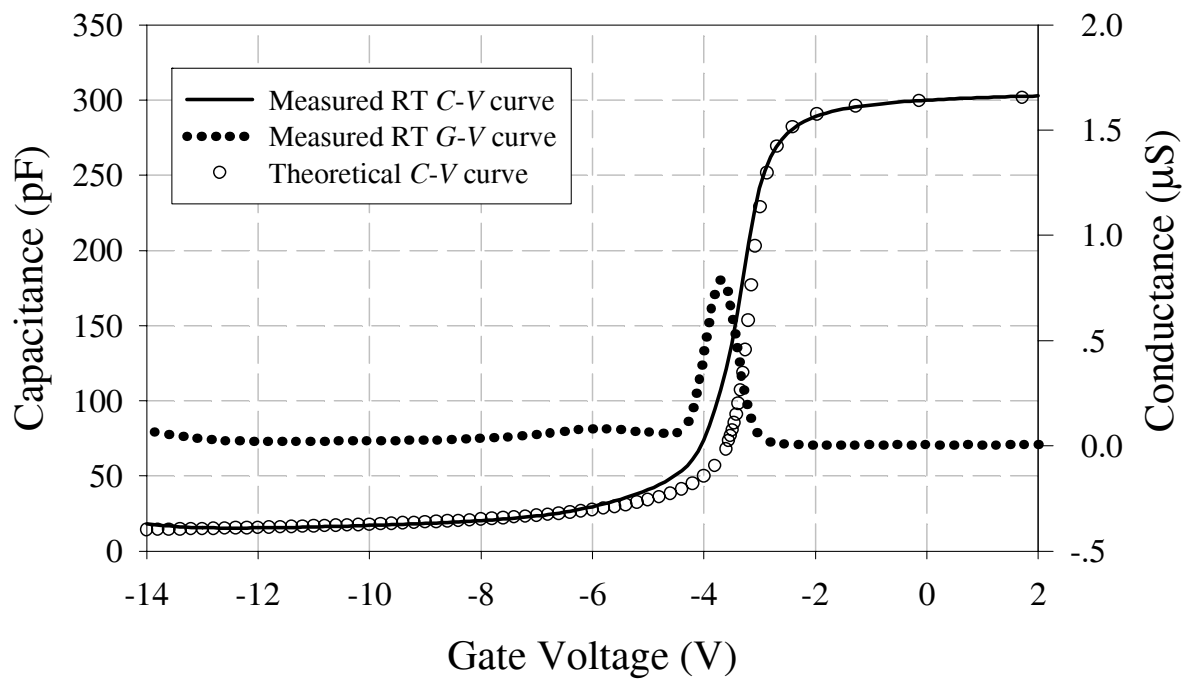

Figure 4 High frequency $C-V$ and $G-V$ curves for the $3 \mathrm{C}-\mathrm{SiC}$ film deposited at $1370{ }^{\circ} \mathrm{C}$ (sample B). 
and small stretch-out observed in the measured as compared to the theoretical $C$ - $V$ curves indicate low interface traps density at the $\mathrm{SiO}_{2} / \mathrm{SiC}$ interface [7]. Similar level of conductance peaks also indicates similar level of interface-trap density for $\mathrm{SiC}$ films deposited at different temperatures. The $C-V$ curves display a negative flat-band voltage shift for both capacitors. The negative flat-band voltage indicates the traps at $\mathrm{SiO}_{2} / \mathrm{SiC}$ interface have an effective value of $2.05 \times 10^{12}$ and $1.91 \times 10^{12}$ electronic charges $/ \mathrm{cm}^{2}$ for samples $\mathrm{A}$ and $\mathrm{B}$, respectively. These results show that good quality oxide can be grown on the $\mathrm{SiC}$ films that are deposited at lower temperature, compared to the conventional deposition temperature.

Current voltage measurements in the MOS capacitor accumulation region were also used to study the quality of the deposited $\mathrm{SiC}$ films on samples A and B. Typical current voltage characteristics of both samples are shown in Figure 5. A smaller leakage current is obtained for sample A, deposited at $1270^{\circ} \mathrm{C}$. This agrees well with the average surface roughness measurement results as the gate leakage current is affected by surface roughness, a smoother $\mathrm{SiC}$ surface makes a smoother $\mathrm{SiC} / \mathrm{SiO}_{2}$ interface and $\mathrm{SiO}_{2}$ surface, and thus a smaller leakage current. It is possible that for the MOS capacitor the surface roughness plays a more important role than the stacking fault density in the $3 \mathrm{C}-\mathrm{SiC}$ films. The yield of the MOS capacitors fabricated on both of the films is about $85 \%$.

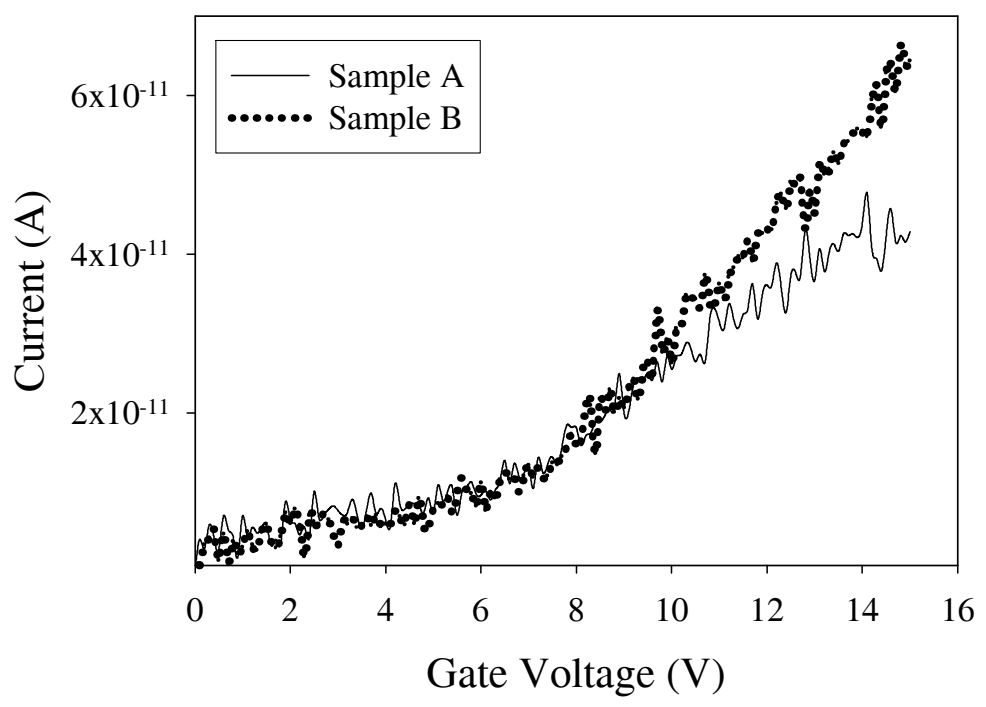

Figure 5 Current-voltage characteristics in the accumulation region for both samples

\section{CONCLUSIONS}

In summary, decreasing the deposition temperature of 3C-SiC films on $\mathrm{Si}$ substrates from $1370^{\circ} \mathrm{C}$ to $1270^{\circ} \mathrm{C}$ does not bring any remarkable negative impact on the interface properties of fabricated MOS capacitors, though the deposited 3C-SiC film has lower stacking fault density at $1370^{\circ} \mathrm{C}$. Gate oxide grown by the $\mathrm{NO}$ process can form a high quality $\mathrm{SiO}_{2} / \mathrm{SiC}$ interface on $\mathrm{SiC}$ films deposited at different temperatures. Current voltage measurement indicated smaller leakage current for the $\mathrm{SiC}$ film deposited at $1270^{\circ} \mathrm{C}$. It is possible that for the MOS capacitor the surface roughness of $\mathrm{SiC}$ film plays a more important role than the stacking fault density in the deposited $3 \mathrm{C}-\mathrm{SiC}$ film. It is practical to deposit MOS capacitor quality $3 \mathrm{C}-\mathrm{SiC}$ films at $1270^{\circ} \mathrm{C}$ on $\mathrm{Si}$ substrates. 


\section{ACKNOWLEDGEMENTS}

The authors would like to thank Dr. Martin Schmidbauer at Institute of Crystal Growth (Berlin, Germany) for the HRXRD rocking curve measurements on the samples.

\section{REFERENCES}

[1] X.M.H. Huang, C.A. Zorman, M. Mehergany, and M.L. Roukes, Nature 421 (2003).

[2] S. Dimitrijev, Microelectron. Eng. 83 (2006) 123.

[3] J. Yun, T. Takahashi, Y. Ishida, H. Okumura, J. Cryst. Growth 291 (2006) 140.

[4] J-H Boo, S. A. Ustin, W. Ho, Thin Solid Film, 343-344 (1999) 650.

[5] F. Ciobanu, G. Pensl, H. Nagasawa, A. Schoner, S. Dimitrijev, K-Y Cheong, V.V. Afanasev and G. Wagner, Mat. Sci. Forum 433-436 (2003) 551.

[6] G. Wagner, D. Schulz, D. Siche, Progress in Crystal Growth and Characterization of Materials 47 (2003) 139.

[7] D.K. Schroder, Semiconductor Material and Device Characterization, 3rd ed. (John Wiley \& Sonsm Inc., Hoboken, New Jersey, 2006), pp. 350-351. 